\title{
Movement Imitation Therapy for Preterm Babies (MIT-PB): a Novel Approach to Improve the Neurodevelopmental Outcome of Infants at High-Risk for Cerebral Palsy
}

\author{
Marina Soloveichick $^{1,2} \cdot$ Peter B. Marschik 3,4,5,6 (D) Ayala Gover ${ }^{1,2}$. \\ Michal Molad ${ }^{1,2} \cdot$ Irena Kessel $^{1,2} \cdot$ Christa Einspieler $^{3}$
}

Published online: 18 November 2019

(C) The Author(s) 2019

\begin{abstract}
To improve the neurodevelopmental outcome in infants with high grade intraventricular haemorrhage and cramped-synchronised (CS) general movements (GMs). Four very preterm infants with intraventricular haemorrhage grade III $(n=3)$ or intraventricular haemorrhage with apparent periventricular haemorrhagic infarction $(n=1)$ were diagnosed with CS GMs at 33 to 35 weeks postmenstrual age. A few days later MIT-PB [Movement Imitation Therapy for Preterm Babies], an early intervention programme, was commenced: the instant an infant showed CS movements, the therapist intervened by gently guiding the infant's limbs so as to manoeuvre and smoothen the movements, thereby imitating normal GM sequences as closely as possible (at least for $10 \mathrm{~min}, 5$ times a day, with increasing frequency over a period of 10 to 12 weeks). After a period of consistent CS GMs, the movements improved. At 14 weeks postterm age, the age specific GM pattern, fidgety movements, were normal in three infants, one infant had abnormal fidgety movements. At preschool age, all participants had a normal neurodevelopmental outcome. This report on four cases demonstrates that mimicking normal and variable GM sequences might have a positive cascading effect on neurodevelopment. The results need to be interpreted with caution and replication studies on larger samples are warranted. Nonetheless, this innovative approach may represent a first step into a new intervention strategy.
\end{abstract}

Keywords Cerebral palsy · Early intervention · Intraventricular haemorrhage · General movements

Peter B. Marschik

peter.marschik@med.uni-goettingen.de; peter.marschik@medunigraz.at

Extended author information available on the last page of the article 


\section{Introduction}

Infants born very preterm ( $<32$ weeks' gestational age) are at increased risk for adverse neurodevelopmental outcome as a result of prenatal or perinatal brain lesion (Patel 2016; Valdez Sandoval et al. 2019). Although the rate of infants developing severe cerebral palsy (CP) has decreased during the last years (McGowan and Vohr 2019), very early preterm birth is still a risk factor for this outcome diagnosis (Burnett et al. 2018; Spittle et al. 2018). According to the EPIPAGE-2 cohort study, the overall rate of CP in children born between 27 and 31 weeks' gestation is $4.3 \%$ (Pierrat et al. 2017). Large cohort studies showed that 28 to $30 \%$ of very preterm infants with intraventricular haemorrhage (IVH) grade III and $60 \%$ of individuals with intraparenchymal haemorrhage (IPH) (Volpe 1998) were later diagnosed with CP (Ancel et al. 2006; Bolisetty et al. 2018; Radic et al. 2015).

The Prechtl general movements assessment (GMA) (Einspieler et al. 2004; Einspieler and Prechtl 2005) enables us to assess the young nervous system reliably, sensitively and non-intrusively during preterm age until about 5 months post-term. Abnormal general movements (GMs) are predictive of an adverse neurological outcome, in particular, of CP (e.g., Prechtl et al. 1997; Einspieler et al. 2013; Bosanquet et al. 2013; Novak et al. 2017). It is mainly the pattern of cramped-synchronised (CS) GMs that predicts spastic CP (with a positive likelihood ratio of 45) if consistently present for several weeks (Ferrari et al. 1990, 2002, 2011; Einspieler and Prechtl 2005; Bruggink et al. 2009; Yang et al. 2012). CS GMs appear rigid and lack the normal smooth and fluent character that characterises normal GMs; limbs and trunk muscles contract almost simultaneously and then relax almost simultaneously (Einspieler et al. 2004; Einspieler and Prechtl 2005). The age of appearance of CS GMs has been associated with the degree of the eventual functional impairment caused by CP: the earlier CS GMs appear, the greater the functional impairment (Ferrari et al. 2002), though CS GMs were hardly observed before 32 weeks (Einspieler et al. 2015).

Based on what we know from a number of studies (e.g., Ferrari et al. 2002; Bruggink et al. 2009; Yang et al. 2012; Morgan et al. 2016a; Kwong et al. 2018), one would expect a significant neurodevelopmental deficit if a preterm infant presents with severe structural (e.g. high grade IVH) and functional impairments (e.g. CS GMs over a period of at least 3 consecutive weeks). Such early identification cries out for early intervention, but we only know little about the effect of intervention that already starts preterm (Hadders-Algra 2014; Silveira et al. 2018; Hutchon et al. 2019).

Considering the high risk of adverse neurological outcome due to severe brain injury accompanied by CS GMs and the inconclusive results of studies on very early intervention, we intended to find out whether a specifically designed intervention, aimed at superimposing fluent and variable GM sequences (i.e. therapist-mediated) has a positive effect on the neurodevelopmental outcome.

\section{Methods}

\section{Case Histories}

From June to December 2012, four very preterm infants (born at 27 to 28 weeks' gestation), two males and two females, were admitted to the Neonatal Intensive Care 
Unit at the Carmel Medical Center, Haifa, Israel. Their cranial ultrasound abnormalities revealed high grade IVH: IVH grade III or IVH with apparent periventricular haemorrhagic infarction (APHI) according to Volpe (2018) in all four infants. Repeated GMA demonstrated CS GMs from 33 or 35 weeks onwards. The infants' clinical data are listed in Table 1; none of the infants received anticonvulsants. All parents gave their informed consent for assessment, intervention, and publication of the results; the ethical committee of the Carmel Medical Center Haifa approved the interventional approach.

\section{Recordings and Assessment of GMs}

Video recordings commenced 3 weeks after birth and were repeated at least thrice by the time the infants were discharged from hospital. In addition, each infant was videotaped twice during the first month after term and once at 14 weeks postterm age (Table 2). The infants were recorded lying in supine during periods of activity (preterm age), or active wakefulness (postterm age), wearing minimal clothing for 3 to 5 min (Einspieler et al. 2004). GMs were classified as normal or abnormal according to the Gestalt perception of the age-specific GM pattern: GMs during preterm age, around term and during the first month postterm age were scored as (a) "normal" if the movement sequence, amplitude, speed and intensity were variable; (b) "poor repertoire" (PR) if the sequence of movement components was monotonous and the amplitude, speed and intensity lacked the normal variability; (c) "cramped-synchronised" (CS) if GMs lacked the usual smoothness and appeared rigid, with limbs and trunk muscles contracting almost simultaneously and then relaxing almost simultaneously; or (d) "chaotic" (Ch) if the amplitude was large, the speed high, and GMs consistently appeared to be abrupt (Einspieler et al. 2004, 2015; Einspieler and Prechtl 2005).

At 14 weeks postterm, the age-specific form of GMs - fidgety movements - was scored as (a) "normal" if small movements of moderate speed with variable acceleration of the neck, trunk and limbs in all directions were present; (b) "abnormal" if the GMs looked like normal fidgety movements though with a greater amplitude, speed and jerkiness; or (c) "absent" if no fidgety movements were observed (Prechtl et al. 1997; Einspieler et al. 2004; Einspieler and Prechtl 2005).

GMs were scored by two certified scorers (M.S. and C.E) on the basis of standard GMA video recordings. At 14 weeks postterm age the concurrent movement repertoire, which includes wiggling-oscillating and swiping arm movements, kicking, movements towards the midline (hand-to-mouth contact, hand-to-hand contact, foot-to-foot contact), and antigravity movements (legs lift with or without hand-to-knee contact) (Einspieler et al. 2008), was scored as "age-appropriate" - or "age-inappropriate", if movements towards the midline and antigravity movements were lacking. Interrater reliability was Kappa $=1.0$ in the GMA and the assessment of the concurrent movements. C.E. was blinded to the clinical history of the cases.

\section{MIT-PB Procedure: Attempting to Optimise the Pattern of GMs}

GMs are produced by a central pattern generator (CPG), a neural network which is probably located in the brain stem. In order to lend variability to the motor output, supraspinal projections and the sensory feedback modulate the CPG activity (Einspieler et al. 2004, 2016). In case of brain injury, the CPG modulation by supraspinal projection is 


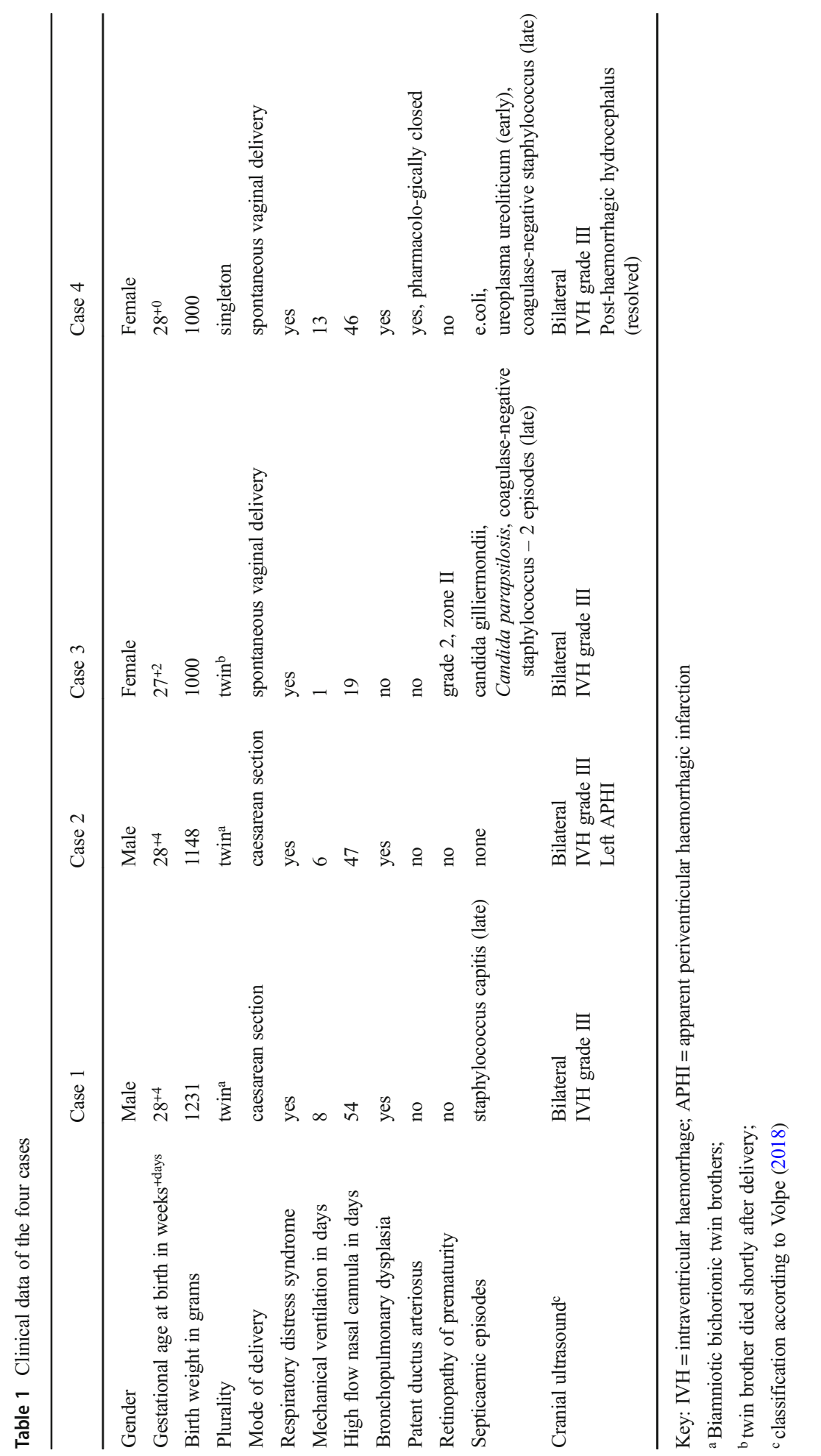


Table 2 Individual developmental trajectories of GMs

\begin{tabular}{|c|c|c|c|c|c|c|c|c|c|c|c|c|c|c|}
\hline $\begin{array}{l}\text { Post-menstrual age } \\
\text { in weeks }\end{array}$ & 27 & 28 & 29 & 30 & 31 & 32 & 33 & 34 & 35 & $36-37$ & $38-39$ & $40-41$ & $42-45$ & 54 \\
\hline Case 1 & & B & & & $\mathrm{PR}^{\mathrm{C}}$ & $\mathrm{PR}^{\mathrm{C}}$ & & CS & & CS & CS & $\mathbf{P R}^{\mathrm{C}}$ & PR & $\begin{array}{l}\mathrm{F}+ \\
\mathrm{AR}\end{array}$ \\
\hline Case 2 & & B & & & $\mathrm{PR}^{\mathrm{C}}$ & $\mathrm{Ch}$ & & CS & & CS & CS & CS & $\mathbf{P R}^{\mathrm{C}}$ & $\begin{array}{l}\mathrm{F}+ \\
\mathrm{IR}\end{array}$ \\
\hline Case 3 & B & & & PR & & $\mathrm{PR}^{\mathrm{C}}$ & & & CS & CS & CS & CS & $\mathbf{P R}^{\mathrm{C}}$ & $\begin{array}{l}\mathrm{F}+ \\
\mathrm{IR}\end{array}$ \\
\hline Case 4 & & B & & & $\mathrm{PR}^{\mathrm{C}}$ & & CS & & CS & & CS & $\mathbf{P R}^{\mathrm{C}}$ & PR & $\begin{array}{l}\mathrm{AF} \\
\mathrm{IR}\end{array}$ \\
\hline
\end{tabular}

Key: $\mathrm{AF}=$ abnormal fidgety movements; $\mathrm{AR}=$ age-appropriate motor repertoire (Einspieler et al. 2004, 2008); $\mathrm{B}=$ birth $\mathrm{Ch}=$ chaotic pattern of GMs; $\mathrm{CS}=$ cramped-synchronised pattern of GMs; $\mathrm{F}+=$ presence of normal fidgety movements; IR = age-inappropriate motor repertoire (Einspieler et al. 2004, 2008); PR = poor repertoire of GMs; $\mathrm{PR}^{\mathrm{C}}=$ poor repertoire of GMs with cramped components

The period in bold indicates intensive intervention by the application of the MIT-PB procedure

limited. Hence, we assume that one way of modulating CPG activity is to move the infant's limbs in a variable mode so as to enhance the variability of sensory feedback.

A few days after CS GMs were diagnosed, the MIT-PB [Movement Imitation Therapy for Preterm Babies] procedure was started (the duration is highlighted in bold in Table 2). MIT-PB was launched by the first author, a neonatologist, in cooperation with a developmental physiotherapist (both are henceforth referred to as "therapists"). The procedure was the following: the instant an infant showed CS movements, the therapists (or a therapist and a parent) intervened by gently guiding the infants' limbs so as to manoeuvre and smoothen their movements, thereby imitating normal GM sequences as closely as possible. Simultaneous extension followed by simultaneous relaxation of the limbs is transformed to smooth and fluent movements by the therapists, i.e. superimposing a variable sequence of movements mimicking normal GMs; e.g., increasing rotatory components, waxing and waning, as well as changing the amplitude of the movements to enhance variability of the repertoire. The therapists had to avoid stressful movements at all times in order to keep the infants calm. Each intervention lasted for at least $10 \mathrm{~min}$. As seen in normal GMs, mimicry GMs were paused in between and when the infants next cramped synchronised movement started, resumed. If an infant started to cry the intervention was paused; the infant was calmed by increased body contact and cuddling. The intervention was repeated at least 5 times per day and the parents were instructed and trained from the very beginning to keep intervening after discharge from the hospital. In this way MIT-PB was maintained until 5 weeks postterm age, i.e. 11 weeks for Cases 1 and 2, 10 weeks for Case 3, and 12 weeks for Case 4 (see Table 2). After discharge from the hospital (at 38 or 39 weeks postmenstrual age) the parents continued to apply MIT-PB as described above; the infants were seen by the therapists on a weekly basis in order to supervise and adjust the parents' manoeuvres.

In addition, parents were trained to handle and posture their infant, which is a standard procedure for all preterm infants born at Carmel Hospital. From 2 to 9 months, all four infants received intervention once a week in accordance with the 
Neurodevelopmental Treatment (Bobath) concept; Case 2 received weekly treatment until 12 months. Subsequently, each child was seen at least once per month by a neurodevelopmental therapist.

\section{Neurological Examination and Follow-up}

During the first 2 years of life, serial clinical assessments included a neurological examination based on Amiel-Tison and Grenier (1983). At the end of the second year, the Bayley Scales of Infant Development, second edition (BSID-II; Bayley 1993) was applied as the third edition was not yet standardized for Israel. In the 5th year of life, the Miller Assessment for Preschoolers (Miller 1988) was used for developmental evaluation (see Table 3).

\section{Results}

All infants showed PR GMs at their first video recording 3 weeks after birth. During these first recordings, cramped components, especially in the lower extremities, could already be observed in Cases 1, 2 and 4. Case 3 only demonstrated cramped components 5 weeks after birth, at 32 weeks postmenstrual age. In Case 2, PR GMs were followed by Ch GMs. At 33 to 35 weeks (i.e. 5 to 8 weeks postnatal), all infants demonstrated CS GMs. Two to 3 days later, MIT-PB was launched as described above. CS GMs continued to be present until termequivalent age. Then GMs improved to PR, although cramped components could be observed every now and then (Table 2).

At 14 weeks postterm age, Cases 1, 2 and 3 showed normal fidgety movements, albeit only intermittently and poorly expressed. Case 4 had abnormal fidgety movements. The concurrent motor repertoire of Case 1 was age-appropriate. Cases 2, 3 and 4 did not show arm and leg movements towards the midline. In Case 2 the asymmetric tonic neck posture was still predominantly present (Table 2 , right column).

At 24 months, all individuals were neurologically normal. Also all BSID-II developmental indices (both mental and psychomotor) were within the normal range; most of them even above the first standard deviation (Table 3). At 4 to 5 years, all cases had normal scores in the Miller Assessment for Preschoolers (Miller 1988).

\section{Discussion}

Very preterm infants often have PR GMs during their first weeks of life (Einspieler et al. 2015; Olsen et al. 2015), but longitudinal GMA reveals that in most preterm infants the quality of GMs normalises by term age (Prechtl et al. 1997; Nakajima et al. 2006). If, however, GMs remain abnormal until 3 to 5 months postterm age, the infant has a high risk for an adverse neurodevelopmental outcome (e.g., Prechtl et al. 1997; Ferrari et al. 2002; Nakajima et al. 2006; Beccaria et al. 2012; Spittle et al. 2013; Einspieler et al. 2016). Especially CS GMs, if consistently present and concurring with severe brain injury, are predictive for the development of spastic cerebral palsy (e.g., Prechtl et al. 1997; Ferrari et al. 1990, 2002; Bruggink et al. 2009; Yang et al. 2012; 


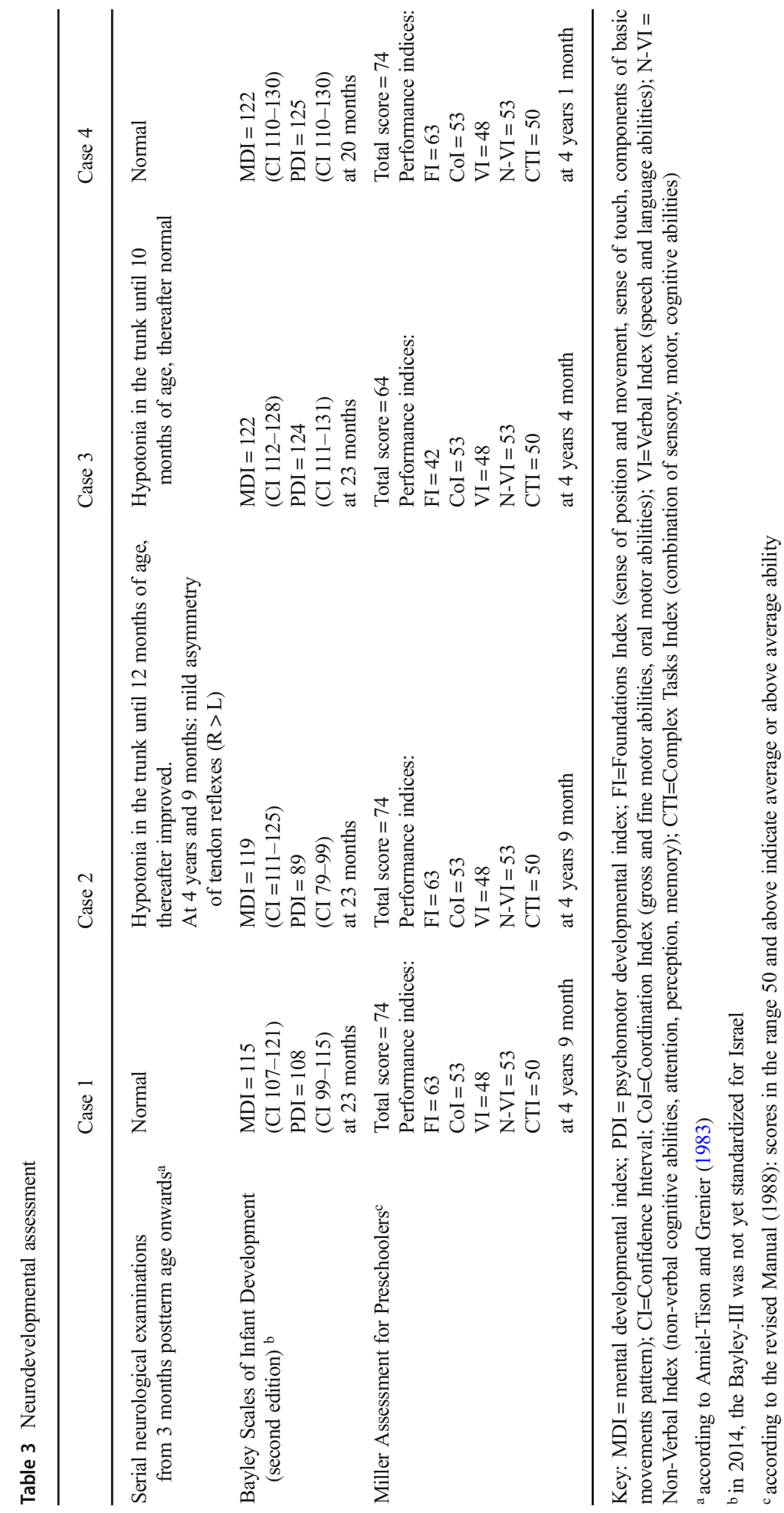


Einspieler et al. 2013; Novak et al. 2017). As far as we can tell, the neurological outcome may only be normal if the CS GMs are transient and the brain injury is less severe (Ferrari et al. 2002).

The four cases of our intervention approach had consistent CS GMs (lasting 5 to 7 weeks, Table 2) but already performed significantly better within the first month post term. All participants developed fidgety movements, although the quality was abnormal in Case 4. To the best of our knowledge, such normalisation of GMs after a comparably long period of CS GMs is unprecedented. Case 1 even had an age-appropriate normal repertoire of concurrent movements, though Cases 2 to 4 showed no movements towards the midline at the 14-week recording. The lack of movements towards the midline is in accordance with a recently published study on extremely preterm infants who showed fewer antigravity movements at 12 weeks postterm age than their peers born at term (Fjørtoft et al. 2016).

For about 25 years, the Prechtl GMA has enabled us to reliably identify infants at high risk for later neurological dysfunctions at a very early stage. GMA is especially powerful if combined with MRI at term age (e.g., Spittle et al. 2009; Ferrari et al. 2011; Bosanquet et al. 2013). On the other hand, there is still few evidence to suggest that such early identification can entail effective early intervention.

Neither a single-session of physiotherapy (Kepenek-Varol et al. 2019) nor a parent-administered early intervention programme applied between 34 and 36 weeks' gestational age (Fjørtoft et al. 2017) had an effect on fidgety movements and the concurrent motor repertoire. Craniosacral therapy applied in the neonatal intensive care unit did also not change the GM quality (Raith et al. 2016). By contrast, an early intervention programme launched already at the 3rd day of life in preterm infants improved the quality of fidgety movements but had no immediate effect on the GMs during preterm and at term age (Ma et al. 2015). Recently, a family-based intervention applied in preterm infants with abnormal GMs revealed positive effects on motor function (Kara et al. 2019). Together with our own promising results, this adds to recent developments promoting family centred intervention programmes such as GAME (Morgan et al. 2016b), COPCA (Hadders-Algra et al. 2017), LEAP-CP (Benfer et al. 2018), or EI-SMART (Hutchon et al. 2019).

We are aware that our pilot study comes along with certain limitations. Our sample is too small to draw general conclusions about the effect of MIT-PB. At this point, it should be seen as starting point and method development that needs to be replicated in larger samples. In addition, intervention studies, as the one reported here, may bear cointervention effects. MIT-PB was done complementary to neurodevelopmental therapy (NDT) as treatment as usual (TAU) procedure. Future large-scale studies are needed to evaluate the effect of MIT-PB in its own right.

Our report is one of the first with a focus on intervention focusing on movement optimization during preterm age and its effect on CS GMs. It is remarkable that three of four children developed normal fidgety movements after a long period of CS GMs and that all four children had a normal neurodevelopmental outcome. The successful application of our MIT-PB procedure might encourage researchers and clinicians to continue testing the impact of mimicking normal and variable GM sequences on the neurodevelopmental outcome, not to mention the benefits of such a simple, parentmediated intervention method. 
Acknowledgements The authors thank the children and parents for their compliance and cooperation. We are grateful to the developmental therapists Miri Harel, Eti Hershon, and Rahel Nadler from the Department of Neonatology at Carmel Medical Center, Haifa; to Miha Tavcar, sciptophil, for copy editing the paper; and to Professor Jeff Sigafoos, a dear friend, for his help in finding the acronym. Peter B Marschik was supported by the FWF Austrian Science Fund (P25241; TCS24) and the Austrian National Bank (OeNB 16430).

Funding Information Open access funding provided by Medical University of Graz.

\section{Compliance with Ethical Standards}

Ethical Approval All procedures involving human participants were in accordance with the ethical standards of the national research committee (the ethical committee of the Carmel Medical Center approved this interventional approach) and with the 1964 Helsinki declaration and its later amendments or comparable ethical standards.

Informed Consent All parents gave their written informed consent to assess the GMs of their children, to apply the MIT-PB procedure, and to publish the results.

Conflict of Interest The authors report no conflict of interests. The authors alone are responsible for the content and writing of the article.

Open Access This article is distributed under the terms of the Creative Commons Attribution 4.0 International License (http://creativecommons.org/licenses/by/4.0/), which permits unrestricted use, distribution, and reproduction in any medium, provided you give appropriate credit to the original author(s) and the source, provide a link to the Creative Commons license, and indicate if changes were made.

\section{References}

Amiel-Tison, C., \& Grenier, A. (1983). Neurological evaluation of the newborn and the infant. New York: Masson.

Ancel, P. Y., Livinec, F., Larroque, B., Marret, S., Arnaud, C., Pierrat, V., Dehan, M., N'Guyen, S., Escande, B., Burguet, A., Thiriez, G., Picaud, J. C., André, M., Bréart, G., Kaminski, M., \& EPIPAGE Study Group. (2006). Cerebral palsy among very preterm children in relation to gestational age and neonatal ultrasound abnormalities: the EPIPAGE cohort study. Pediatrics, 117, 828-835.

Bayley, N. (1993). Bayley scales of infant development (2nd ed.). San Antonio: The Psychological Corporation. Harcourt Brace \& Company.

Beccaria, E., Martino, M., Briatore, E., Podestà, B., Pomero, G., Micciolo, R., Espa, G., \& Calzolari, S. (2012). Poor repertoire general movements predict some aspects of development outcome at 2 years in very preterm infants. Early Human Development, 86, 393-396.

Benfer, K. A., Novak, I., Morgan, C., Whittingham, K., Khan, N. Z., Ware, R. S., Bell, K. L., Bandaranayake, S., Salt, A., Ghosh, A. K., Bhattacharya, A., Samanta, S., Moula, G., Bose, D., Tripathi, S., \& Boyd, R. N. (2018). Community-based parent-delivered early detection and intervention programme for infants at high risk of cerebral palsy in a low-resource country (Learning through Everyday Activities with Parents (LEAP-CP)): protocol for randomised controlled trial. British Medical Journal Open, 8, e021186.

Bolisetty, S., Tiwari, M., Sutton, L., Schindler, T., Bajuk, B., Lui, K., \& New South Wales and the Australian Capital Territory Neonatal Intensive Care Units' Data Registry. (2018). Neurodevelopmental outcomes of extremely preterm infants in New South Wales and the Australian Capital Territory. Journal of Paediatrics and Child Health. https://doi.org/10.1111/jpc.14323.

Bosanquet, M., Copeland, L., Ware, R., \& Boyd, R. (2013). A systematic review of tests to predict cerebral palsy in young children. Developmental Medicine and Child Neurology, 55, 418-426. 
Bruggink, J. L., Cioni, G., Einspieler, C., Maathuis, C. G., Pascale, R., \& Bos, A. F. (2009). Early motor repertoire is related to level of self-mobility in children with cerebral palsy at school age. Developmental Medicine and Child Neurology, 51, 878-885.

Burnett, A. C., Cheong, J. L. Y., \& Doyle, L. W. (2018). Biological and social influences on the neurodevelopmental outcomes of preterm infants. Clinics in Perinatology, 45, 485-500.

Einspieler, C., \& Prechtl, H. F. (2005). Prechtl's assessment of general movements: a diagnostic tool for the functional assessment of the young nervous system. Mental Retardation and Developmental Disabilities Research Reviews, 11, 61-67.

Einspieler, C., Bos, A. F., Ferrari, F., Cioni, G., \& Prechtl, H. F. R. (2004). Prechtl's method on the qualitative assessment of general movements in preterm, term and young infants. London: Mac Keith Press.

Einspieler, C., Marschik, P. B., \& Prechtl, H. F. (2008). Human motor behaviour. Prenatal origin and early postnatal development. Journal of Psychology, 216, 148-154.

Einspieler, C., Marschik, P. B., Bos, A. F., Ferrari, F., Cioni, G., \& Prechtl, H. F. (2013). Early markers for cerebral palsy: insights from the assessment of general movements. Future Neurology, 7, 709-717.

Einspieler, C., Marschik, P. B., Pansy, J., Scheuchenegger, A., Krieber, M., Yang, H., Kornacka, M. K., Rowinska, E., Soloveichik, M., \& Bos, A. F. (2015). The general movement optimality score: a detailed assessment of general movements during preterm and term age. Developmental Medicine and Child Neurology, 58, 361-368.

Einspieler, C., Bos, A. F., Libertus, M. E., \& Marschik, P. B. (2016). The general movement assessment helps us to identify preterm infants at risk for cognitive dysfunction. Frontiers in Psychology, 7, 406.

Ferrari, F., Cioni, G., \& Prechtl, H. F. (1990). Qualitative changes of general movements in preterm infants with brain lesions. Early Human Development, 23, 193-231.

Ferrari, F., Cioni, G., \& Einspieler, C. (2002). Cramped synchronized general movements in preterm infants as an early marker for cerebral palsy. Archives of Pediatrics \& Adolescent Medicine, 156, 460-467.

Ferrari, F., Todeschini, A., Guidotti, I., Martinez-Biarge, M., Roversi, M. F., Berardi, A., Ranzi, A., Cowan, F. M., \& Rutherford, M. A. (2011). General movements in full-term infants with perinatal asphyxia are related to basal ganglia and thalamic lesions. The Journal of Pediatrics, 158, 904-911.

Fjørtoft, T., Evensen, K. A. I., Øberg, G. K., Songstad, N. T., Labori, C., Silberg, I. E., Loennecken, M., Møinichen, U. I., Vågen, R., Støen, R., \& Adde, L. (2016). High prevalence of abnormal motor repertoire at 3 months corrected age in extremely preterm infants. European Journal of Paediatric Neorology, 20, 236-242.

Fjørtoft, T., Ustad, T., Follestad, T., Kaaresen, P. I., \& Øberg, G. K. (2017). Does a parent-administrated early motor intervention influence general movements and movement character at 3months of age in infants born preterm? Early Human Development, 112, 20-24.

Hadders-Algra, M. (2014). Early diagnosis and early intervention in cerebral palsy. Frontiers in Neurology, 5, 1-13.

Hadders-Algra, M., Boxum, A. G., Heilkema, T., \& Hamer, E. G. (2017). Effect of early intervention in infants at very high risk of cerebral palsy: a systematic review. Developmental Medicine and Child Neurology, 59, 246-258.

Hutchon, B., Gibbs, D., Harniess, P., Jary, S., Crossley, S. L., Moffat, J. V., Basu, N., \& Basu, A. P. (2019). Early intervention programmes for infants at high risk of atypical neurodevelopmental outcome. Developmental Medicine and Child Neurology. https://doi.org/10.1111/dmen.14187.

Kara, O. K., Sahin, S., Yardımci, B. N., \& Mutlu, A. (2019). The role of the family in early intervention of preterm infants with abnormal general movements. Neurosciences (Riyadh), 24, 101-109.

Kepenek-Varol, B., Tanrıverdi, M., İșcan, A., \& Alemdaroğlu-Gürbüz, İ. (2019). The acute effects of physiotherapy on general movement patterns in preterm infants: a single-blind study. Early Human Development, 131, 15-20.

Kwong, A. K. L., Fitzgerald, T. L., Doyle, L. W., Cheong, J. L. Y., \& Spittle, A. J. (2018). Predictive validity of spontaneous early infant movement for later cerebral palsy: a systematic review. Developmental Medicine and Child Neurology, 60, 480-489.

Ma, L., Yang, B., Meng, L., Wang, B., Zheng, C., \& Cao, A. (2015). Effect of early intervention on premature infants' general movements. Brain \& Development, 37, 387-393.

McGowan, E. C., \& Vohr, B. R. (2019). Neurodevelopmental follow-up of preterm infants: What is new? Pediatric Clinics of North America, 66, 509-523.

Miller, L. J. (1988). MAP. Miller Assessment for Preschoolers. San Antonio: Pearson.

Morgan, C., Crowle, C., Goyen, T. A., Hardman, C., Jackman, M., Novak, I., \& Badawi, N. (2016a). Sensitivity and specificity of general movements assessment for diagnostic accuracy of detecting cerebral palsy early in an Australian context. Journal of Paediatrics and Child Health, 52(1), 54-59.

Morgan, C., Novak, I., Dale, R. C., Guzzetta, A., \& Badawi, N. (2016b). Single blind randomized controlled trial of GAME (Goals-Activity-Motor Enrichment) in infants at high risk of cerebral palsy. Research in Developmental Disabilities, 55, 256-257. 
Nakajima, Y., Einspieler, C., Marschik, P. B., Bos, A. F., \& Prechtl, H. F. R. (2006). Does a detailed assessment of poor repertoire general movements help to identify those infants who will develop normally? Early Human Development, 82, 53-59.

Novak, I., Morgan, C., Adde, L., Blackman, J., Boyd, R. N., Brunstrom-Hernandes, J., Cioni, G., Damiano, D., Darrah, J., Eliasson, A. C., de Vries, L. S., Einspieler, C., Fahey, M., Fehlings, D., Ferriero, D. M., Fetters, L., Fiori, S., Forssberg, H., Gordon, A. M., Greaves, S., Guzzetta, A., Hadders-Algra, M., Harbourne, R., Kakooza-Mwesige, A., Karlsson, P., Krumlinde-Sundholm, L., Latal, B., LoughranFowlds, A., Maitre, N., McIntyre, S., Noritz, G., Pennington, L., Romeo, D. M., Shepherd, R., Spittle, A. J., Thornton, M., Valentine, J., Walker, K., White, R., \& Badawi, N. (2017). Early, accurate diagnosis and early intervention in cerebral palsy advances in diagnosis and treatment. Journal of American Medical Association Pediatrics, 171, 897-907.

Olsen, J. E., Brown, N. C., Eeles, A. L., Lee, K. J., Anderson, P. J., Cheong, J. L. Y., Doyle, L. W., \& Spittle, A. J. (2015). Trajectories of general movements from birth to term-equivalent age in infants born $<30$ weeks' gestation. Early Human Development, 91, 683-688.

Patel, R. M. (2016). Short- and long-term outcomes for extremely preterm infants. American Journal of Perinatology, 33, 318-328.

Pierrat, V., Marchand-Martin, L., Arnaud, C., Kaminski, M., Resche-Rigon, M., Lebeaux, C., Bodeau-Livinec, F., Morgan, A. S., Goffinet, F., Marret, S., Ancel, P. Y., \& EPIPAGE-2 writing group. (2017). Neurodevelopmental outcome at 2 years for preterm children born at 22 to 34 weeks' gestation in France in 2011: EPIPAGE-2 cohort study. British Medical Journal, 358, j3448.

Prechtl, H. F., Einspieler, C., Cioni, G., Bos, A. F., Ferrari, F., \& Sontheimer, D. (1997). An early marker for neurological deficits after perinatal brain lesions. The Lancet, 349, 1361-1363.

Radic, J. A., Vincer, M., \& McNeely, P. D. (2015). Outcomes of intraventricular hemorrhage and posthemorrhagic hydrocephalus in a population-based cohort of very preterm infants born to residents of Nova Scotia from 1993 to 2010. Journal of Neurosurgery: Pediatrics, 15, 580-588.

Raith, W., Marschik, P. B., Sommer, C., Maurer-Fellbaum, U., Amhofer, C., Avian, A., Löwenstein, E., Soral, S., Müller, W., Einspieler, C., \& Urlesberger, B. (2016). General movements in preterm infants undergoing craniosacral therapy: A randomised controlled pilot-trial. BMC Complementary and Alternative Medicine, 16, 12.

Silveira, R. C., Mendes, E. W., Fuentefria, R. N., Valentini, N. C., \& Procianoy, R. S. (2018). Early intervention program for very low birth weight preterm infants and their parents: a study protocol. BMC Pediatrics, 18, 268.

Spittle, A. J., Boyd, R. N., Inder, T. E., \& Doyle, L. W. (2009). Predicting motor development in very preterm infants at 12 months' corrected age: the role of qualitative magnetic resonance imaging and general movements assessments. Pediatrics, 123, 512-517.

Spittle, A. J., Spencer-Smith, M. M., Cheong, J. L. Y., Eeles, A. L., Lee, K. J., Anderson, P. J., \& Doyle, L. W. (2013). General movements in very preterm children and neurodevelopment at 2 and 4 years. Pediatrics, 132, e452-e458.

Spittle, A. J., Morgan, C., Olsen, J. E., Novak, I., \& Cheong, J. L. Y. (2018). Early diagnosis and treatment of cerebral palsy in children with a history of preterm birth. Clinics in Perinatology, 45, 409-420.

Valdez Sandoval, P., Hernández Rosales, P., Quiñones Hernández, D. G., Chavana Naranjo, E. A., \& García Navarro, V. (2019). Intraventricular hemorrhage and posthemorrhagic hydrocephalus in preterm infants: diagnosis, classification, and treatment options. Childs Nervous System, 35, 917-927.

Volpe, J. J. (1998). Brain injury in the premature infant: overview of clinical aspects, neuropathology, and pathogenesis. Seminars in Pediatric Neurology, 5, 135-151.

Volpe, J. J. (2018). Preterm intraventricular hemorrhage/posthemorrhagic hydrocephalus. In Volpe's neurology of the newborn (6th ed., pp. 637-698). Philadelphia: Elsevier.

Yang, H., Einspieler, C., Shi, W., Marschik, P. B., Wang, Y., Li, H., Liao, Y. G., \& Shao, X. M. (2012). Cerebral palsy in children: movements and postures during early infancy, dependent on preterm vs. full term birth. Early Human Development, 88, 837-843.

Publisher's Note Springer Nature remains neutral with regard to jurisdictional claims in published maps and institutional affiliations. 


\section{Affiliations}

\section{Marina Soloveichick ${ }^{1,2}$ • Peter B. Marschik ${ }^{3,4,5,6}$ - Ayala Gover ${ }^{1,2}$ - Michal Molad $^{1,2} \cdot$ Irena Kessel $^{1,2} \cdot$ Christa Einspieler $^{3}$}

1 Neonatal Intensive Care Unit, Lady Davis Carmel Medical Center, Haifa, Israel

2 The Ruth and Bruce Rappaport Faculty of Medicine, Technion, Haifa, Israel

3 Research Unit iDN - interdisciplinary Developmental Neuroscience, Division of Phoniatrics, Medical University of Graz, Graz, Austria

4 Department of Child and Adolescent Psychiatry and Psychotherapy, University Medical Center Göttingen, Göttingen, Germany

5 Leibniz ScienceCampus Primate Cognition, Göttingen, Germany

6 Center of Neurodevelopmental Disorders (KIND), Department of Women's and Children's Health, Karolinska Institutet, Stockholm, Sweden 